\title{
Study of the Relationship of Papillary Pattern Criminal Conduct of Human
}

\author{
Vasily Yarovenko ${ }^{1}$ \\ ${ }^{1}$ Law school, Far Eastern University, Vladivostok, Russian Federation \\ Correspondence: Vasily Yarovenko, Law school, Far Eastern University, Vladivostok, 690091, Russian \\ Federation. E-mail: yarovenko.vv@dvfu.ru
}

Received: February 12, 2015 Accepted: June 11, 2015 Online Published: June 23, 2015

doi:10.5539/ass.v11n16p349

URL: http://dx.doi.org/10.5539/ass.v11n16p349

\begin{abstract}
Reviewed studies by various authors on the relationship of papillary pattern of fingers and possible human behavior. Research in this direction will make it possible to establish the existence of dermatoglyphic patterns and create the information base on which to justify probable search forensic model of criminal. The author substantiates the conclusion whether further studies not only the types of dermatoglyphic methods of papillary pattern and their ratio to the fingers, but also kind, shape and other characteristics of dermatoglyphic papillary pattern for more complete information about the subject.
\end{abstract}

Keywords: fingerprinting, dermatoglyphics, crime, criminal, identity, papillary patterns, search engine model

\section{Introduction}

Requirements to combat crimes, especially with the increase in the number of serious, now require the development of new prevention methods, which include, inter alia, the study of dermatoglyphicu structure of the papillary pattern, combed through each finger, palm, shared account combed through other signs. Previously individual scientists, the view was expressed that the criminals have avilable papillary pattern. To confirm the provisions of the present study was carried out by the author.

\section{Methodology}

Research was conducted from 2010-2015 years. Theoretical studies have be $\mathrm{n}$ analysed in previous years by other authors, conducted various analogies and comparisons have also been studied papillary patterns perpetrators of serial murders. Results were compared to establish existing dermatoglyphics features.

\section{Discussion}

Papillary patterns palmprints are object of study as the fingerprinting system, and subject of study of the genetic features of functional properties of the human body: the predisposition to certain diseases; susceptibility to certain types of occupations; engaging in certain activities; human behavior in extreme situations; other behavioral characteristics; compatibility of couples (Guseva, 2010; Zvyagin \& Rakitin, 2012; Yarovenko, 2011).

The founder of the scientific study of dermatoglyphic links and behavioral characteristics considered English scholar N. Jaguin, who discovered the high occurrence of the curls have condemned with deformations in the moral sphere (Jaguin, 1934).

Currently needs to combat crimes, especially with the increase in the number of serious, require the development of new preventive measures, which include genetic methods, in particular, dermatoglyphic. In science was expressed a different opinion (Andreeva \& Kitaev, 2009). Scientists and practices pay attention to the results of medical dermatoglifike to establish a link between the characteristics of papillary pattern, human behavior and its external appearance (Yarovenko \& Chistikin, 1994; Mazur, 2009; Badikov, 2012; Vlasov, 2012; Efremov, 2014). So, A. Titarenko found that criminals in $94.1 \%$ of the observed asymmetry bed account (Titarenko, 2010).

In 1998, scientists investigated the dermatoglyphics 17 perpetrators of serial murders for sexual reasons, among them Chikatilo, Golovkin, Asimov. To determine predisposition to serial killings, in their view, you must set the type and appearance of papillary pattern and their relationship to the hands.

Dermatoglyphics serial killers showed signs of left handed: asymmetric patterns of thumbs with a more complex pattern-baby curl on the left hand and the more simple-loop on the right hand. Chikatilo was left-handed, he's on 
the big toe of the right arm there was a loop pattern, and on the thumb of the left hand is, whorl. Based on the results, the scientists have concluded that the deviant behavior. Maniac killer may be a rare constitutional type of the central nervous system, abbreviated type left handed (Bogdanov, Samihenko, \& Hvylya-Olinter, 1998).

If this is indeed the case, fingerprint card Chikatilo is a marker of serial killers. In our view, this conclusion should be critical of, first, the authors conducted an incomplete dermatoglyphic study of papillary pattern based on Chikatilo only papillary pattern of distal phalanges of fingers on fingerprint card. Conclusion was reached taking into account the types of papillary pattern and their locations on your fingers. Other dermatoglyphic symptoms are not studied, perhaps because of their absence on the fingerprint card, either because of their being. And this, we believe, indicative of incomplete dermatoglyphickoj picture of papillary pattern. In particular, there is no study of the palm dermatoglyphic thenar and hypothenar uzornost': finger triradiusy, bed size of account between the vital triradiusami, pronounced sgibatel'nyh folds and others (Yarovenko \& Kitaev, 2014).

Secondly, the authors focused on only papillary patterns of distal phalanges of fingers Chikatilo, who had the typical form, without allowing the analysis of fingerprint cards of other serial killers, in particular, Golovkin. To establish the similarity of papillary pattern we studied fingerprint card Golovkin, brutally killing 10 boys and adolescents for sexual motives in his garage.

The Golovkin, on his right hand were: L, L, L, L, L; on the left hand L, L, L, L, L. Form papillary pattern has features. The thumb, on a nameless finger of the right hand, and the thumb, and the nameless finger of the left hand there is dysplasia. In addition, the ring finger of the left hand in the center of the pattern has the form indefinite.

Total combed through the right hand-left hand, 42-60. Delta index-10. Right thumb loop pattern, the thumb of the left hand hinge.

Controversy also is, in our view, the finding of the existence of left handed when combined in the right hand thumb loop pattern, and on the thumb of the left hand - pinstripe. This is a personal property can be set by means of interrogation, investigation experiment, but not on the basis of the study of papillary pattern, which contains neither common nor private signs to dermatoglyphic methods set out not only left handed, but also has a certain type.

We also examined the dermatoglyphics, Golovkin, famous serial killers who committed their crimes in various regions of the country, in different years and for various reasons. We have also, as Chikatilo papillary pattern type and their location on the fingers. To establish any of dermatoglyphic features and matches in the group, we not only compared with prints of Chikatilo, but compared with each other. With a view to establishing possible overlap, we have calculated the total propeller score of each hand, only people with high-quality prints of traces.

So, Ershov killed 19 people (17 women), is serving a sentence of life imprisonment. All patterns whorls. The finger of the right hand has a whorls spiral pattern, set at an angle. On the forefinger of the right hand has whorl in the left lateral zone. The thumb and forefinger of the left hand there is dysplasia Ershova.

Kuznetsov killed when rape with particular cruelty in Russia and Ukraine 10 girls. On his right hand were: W, A, L, L, L, and the left hand W, L, L, L, L. large fingers of the right and left hands are complex whorls patterns.

Slivko from 1964 to 1985 years killed for sexual reasons with particular cruelty, 7 boys and another 33 boys alone, hung in a wooded area, simulating (death pioneers), but then found out the loop, led them in feeling and took an oath not to tell anyone about this. He led the tourist Club. On his right hand were: L, W, W, and W, W; d on the left hand, A, $\mathrm{L}, \mathrm{A}, \mathrm{W}, \mathrm{L}$. On the right hand and left hand thumb, index and middle have complex patterns.

Shipilov killed in the rape of 12 women. In 2000, convicted to life imprisonment. On his right hand are: L,W, L, L, P; on the left hand - L, L, L, L, L. Patterns of finger as the right hand and the left have the dysplasia, short lines, lots of points.

For the analysis of dermatoglyphic features located on the fingerprint cards. Snapshots of the fingerprint cards are contained in article (Yarovenko \& Kitaev, 2014). We have grouped as follows:

- The thumb of his right hand and left hand whorl pattern was at Jurika, Kozlova, Kuznetsova, Sukletina, Cumana;

- The thumb of his right hand, whorl pattern, the left hand Петля, дуга, завиток loop, was at Bratilova;

- The thumb of his right hand and left hand hinge pattern at Golovkin, Fokina, Shepilova;

- Right thumb loop pattern, left hand arch was Slivko;

- The ring finger of the right hand and left hand zavitkovymi designs were Gridin, Ershov, Kitaev, Slivko, Stankevich, Hrapov, Yudina. Chyki; 
- The ring finger of the left hand has a whorl pattern at Retunskogo;

- The ring finger of the right hand whorl pattern was Fokina, Tsukanova.

Total rowing through the right hand and left hand:

- Total combed through the right hand 40-50 had three people;

- Total combed through the left hand 40-50 was five people;

- Total combed through the right arm 51-60 had three people;

- Total combed through the left arm 51-60 had one person;

- Total combed through the right hand 61-70 had two people;

- Total combed through the left hand 61-70 was five people;

- Total combed through the right hand 71-80 had six people;

- Total combed through the left hand 71-80 had two people;

- Total combed through the right hand 81-90 had one and people;

- Total combed through 81-90 left hands zero people;

- Total combed through the right hand 91-100 zero people;

- Total combed through the left hand 91-100 of one person;

- Total combed through hand 101-110 had two people;

- Total combed through hand 101-110 zero people.

The most common total rack, right hand was 71-80 with six people following common is the total score of the left hand combed 61-70 for five.

Delta index was: 10 had two faces; 11 had 5; 12 had two; 13 have 4 people; 14 had one; 17 had one; 19 had one; 20 had three. The most common codes 11, 12, and then 20.

Study shows lack of coincidence of dermatoglyphic traits in Chikatilo and other criminals. There are matches of dermatoglyphic traits in different individuals. However, this coincidence cannot be considered as an established pattern of deviant behavior due to the small number of fingerprint cards (Yarovenko \& Kitaev, 2014).

A similar conclusion was made and E. Mazur: "Developed and proposed in practical activities of dermatoglyphic methods using logistic regression to predict the different human traits. For example, with a probability of $72-90 \%$ for males and $81-98 \%$ of women may have such significant signs of how tall sizes. And then she says: "However, in the study of obhvatnyh indicators, it was found that the use of the methods of statistical processing is not allowed to create the correct diagnostic model. The accuracy of these parameters in males was only $65-70 \%$, while the females, these same indicators did not have statistically significant evaluation (Mazur, 2014).

G. Mukhin \& O. Karazej \& D. Isutin-Fedotkov the dermatoglyphic studies have received information about the specifics of trace-representations of papillary pattern palm surface, in particular, data on the on the relationship papillary pattern with both physiological and pathological features of the nervous system; signs indicating deviations from the norms of credible; the differences between the sick epilepsy, schizophrenia, chronic alcoholism and healthy (Mukhin, Karazej, \& Isutin-Fedotkov, 2006).

To identify private dermatoglyphic traits of serial killers, K. Badikov offers fingerprint testing first (large) fingers, taking into account the psihodermatoglyphic cookies congenital abnormalities of the CENTRAL NERVOUS SYSTEM and mind. These markers based on the study of how quantitative indicators (combed through, the number of islets) and geometric (offset Center of papillary pattern relative to the Center, the Delta angle measurement) and descriptive (shape and deformation of papillary lines, pronounced sgibatel'nyh folds, trimming the width, dysplasia, etc.) (Badikov, 2003).

It found that the killers are characterized by: high loop patterns-80\%; no symmetry pattern zavitkovogo- $80 \%$; different angle of papillary pattern homogeneous fingers on $20-30^{\circ}$, as well as the presence of Islet in the center of the pattern; deformation of papillary lines in the centre of papillary pattern; tab on the top of papillary pattern in the shape of a cone; deformation of papillary lines that make up the underlying stream (Badikov, 2007).

Number of papillary lines in the pattern (base flow) points to the markers of the moral qualities and levels of social adaptation (Badikov, 2012). For isteroidnyh personalities characteristic: high location pattern; in the centre there is the "island"; center of papillary pattern shifted to $30^{\circ}$ in ul'narnuû side (mark the right first finger); short 
papillary lines located in the underlying stream and the top of the pattern does not match (Badikov, 2012).

K. Badikov considers study private attributes of papillary pattern fingers socially dangerous criminal dissociation type "dotted scallops", the center of the pattern -"island"; the presence of two or more Islands in the center of the pattern; an increase in the number of "islands "on the periphery of the pattern; number of papillary lines in the pattern (base flow); high-mounted center of papillary pattern; pattern shifted in ul'narnuû or radial direction; short papillary lines located in the underlying stream and the top of the pattern. Among those with steady mentality and a high level of adaptation of these criteria they are not (Badikov, 2011).

He also proposed a methodology for studies of papillary pattern trace identities based on angle measurement of the del'ta to solve diagnostic tasks. In general, for a system of persons convicted of murder is typical: in $90 \%$ of cases the curvature of one or all parts of the pattern (center, top, sidebar, footer) regardless of its kind; $65 \%$ of dysplasia; $60 \%$ of "islets" of papillary lines in various areas, including outside of papillary pattern (Badikov, 2011).

According to A. V. Vlasov, the propensity to deviantnomu behavior can be set on papillary patterns pointing fingers left and right hand. for persons with diviantnym behavior is characterized by typical minucius and atypical early embryonic cell division, with its distinctive feature in each of the five variants of the pluripotency of embryonic leaves (rotation) (in progress or regression), representing thus an individual genome (the $\mathrm{L}$ and $\mathrm{R}$ arm, for example). From a person who encroaches on the lives of law enforcement officials (article 317 of the Criminal Code), the thumb should be loop, pattern, and the unnamed - whorl. This combination must be on both hands. For those who are prone to escape, on the left and right pointing fingers has dual hinge or a compound pattern, formed from two loop patterns (Vlasov, 2012). Determining the type of behavioral adaptation, in his view, could be held to form papillary pattern pointing the fingers of both hands (Vlasov, 2012).

A similar view is shared by the $\mathrm{O}$. A. Sokolova, who took that drug users, or prone to their use, characteristic are the simplified patterned shape (arch, patterns with low bed account no palm lines or patterns) (Sokolova, 2013).

In dermatoglyphic form is a pattern of papillary lines formed in the period of its formation under the influence of various factors which have affected the woman's body. Form 18 types of papillary pattern are highlighted on the balls of your toes, from them-12 major and 6 extra. To include patterns, which is difficult to take a clear decision? This type can be attributed not only to complex drawings, but not very high quality prints: controversial loop-arch patterns; controversial loop-whorl patterns of primary loop characteristic; controversial loop-whorl patterns with primary whorl feature; loop patterns with an uncertain drawing heads loops; whorl patterns obtained with the drawing center; poorly defined patterns with two or more types of drawings (Mazur, 2009).

Form of papillary pattern can be used to obtain more information on the subject of dermatoglyphic methods. Form papillary pattern available on the fingerprint cards at their study to determine whether laws and create the information base on which can be substantiated by credible search forensic model of the subject. The existing standard fingerprint cards are of interest for researchers of dermatoglyphic (Yarovenko, 2014).

Interest, we believe, could represent study M. O. Zoroastrov genetic bases of suicide among residents of the Tyumen region. They found that in a group of people with suicidal tendencies, there are reliable differences from the control group on a number of core topics system. In particular, characteristic of the inhabitants of the Tyumen region is to reduce the frequency of fibulârnyh loops at first the fingers and their frequency on all other toes of both feet, on both feet has been an increase in the frequency of whorl patterns on third fingers (Zoroastrov, 2006).

A similar study on the materials of the Irkutsk region conducts R. G. Ardashev, who believes, that a predisposition to suicide, you must assign the dermatoglyphic examination scallops the skin of the hands and feet of (Ardashev, 2013).

Forensic scientist's dermatoglyphic studies conducted using special methods of obtaining complete prints of traces of hands, allowing you to get more reliable results. So, I. S. Efremov researched prints scallops skin distal phalanges of fingers (uzornost' and combed through) and palm (definition places the main palm line endings, uzornost' hands, combed through, the palm corners). In the control group were studied 101 men, major groups, the 332 men: men who were convicted under article 111 of the CRIMINAL CODE-intentional infliction of serious harm to health 125; man sentenced under article 105 of the CRIMINAL CODE-intentional killing 106; the men, convicted under article 131-101 rape. The total number of examined amounted to 433 .

Identify features of the structure of scallops skin, which reflect the genetic aspects of aggression, therefore, persons who have committed certain offences (murder, intentionally causing serious bodily injury, rape), a complex of dermatoglyphic traits characteristic of individuals with increased aggressiveness, that is prone to 
deviantnomu behavior (Efremov, 2014).

\section{Conclusion}

Thus, the study of different scientists in the field of forensic and criminalistics dermatoglyphic, demonstrate the need to relate the papillary pattern with criminal conduct of human with the subsequent analysis of motives of his behavior and searchable forensic identification model to search for the unknown offender, as well as improving preventive measures.

To establish signs system, indicating a predisposition to deviantnomu behavior, it is necessary to conduct a full study of all dermatoglyphic of the fingers and palms, received special treatment method that will create a more complete picture. first of all, you need to establish quantitative indicators (number of lines between certain points in the palm of your hand, which tend to be triradiusy), describe the form and severity of sgibatel'nyh folds, comb width, dysplasia, etc. To improve the accuracy of the method are important dermatoglyphicogo the publication of the results of the statistical analysis of investigative practices. Dermatoglyphicheskie features you must use to find genetic bases of human propensity to commit crimes, as well as markers of behavior and building a forensic search model of personality.

\section{References}

Andreeva, T., \& Kitaev, N. (2009). Search serial killers: Anti-scientific recommendations. Materials 14-th all-Russia scientific the Conference. Irkutsk.

Ardashev, R. (2013). Knowledge management system in determining the existence of a true suicide and its simulation. Irkutsk.

Badikov, K. (2003). Dermatoglyphic research in forensic search engine methodology model of personality. Vladivostok.

Badikov, K. (2007). Psihodermatoglifika as an integrated model of morpho-functional human potential (DSP). Vladivostok.

Badikov, K. (2011). Psihodermatoglifika: concept, systems, and techniques: Monograph. Vladivostok.

Badikov, K. (2012). Psihodermatoglifikij method of comprehensive study traces hand: Concepts, methods, prospects of development. LAMBERT Academic Publishing.

Bogdanov, N., Samihenko, S., \& Hvylya-Olinter, A. (1998). Dermatoglyphics serial killers. Psychology, 4, 64.

Efremov, I. (2014). Dermatoglyphics characteristics of perpetrators of crimes against life and health. Tyumen.

Guseva, I. (2010). Finger human patterns. Morphology. Morphogenesis. Genetics. Dermatoglyphics as a marker in the medical and sports anthropology.

Mazur, E. (2014). Dermatoglyphic methods use in uncovering and investigating. The materials of the all-Russian scientific conference. Tomsk.

Mazur, E. M. (2009). Dermatoglyphics in predicting physical and constitutional, foreign identification signs of man. Moscow.

Mukhin, G., Karazej, O., \& Isutin-Fedotkov, D. (2006). Criminalistics dermatoglyphics: Waters. Minsk.

Sokolova, O. (2013). Development psychological system and its possibilities in the detection and investigation of crimes. Tyumen.

Titarenko, A. (2010). The use of the data in the investigation of dermatoglyphic investigation. Retrieved from http:/conf.sfu-kras.ru/sites/mn2010/section10.html

Vlasov, A. (2012). Report "Visual express method of psychological personality on patterns of papillary lines pointing fingers". Retrieved December 2, 2012, from http//alexwlwl@yandex.ru

Vlasov, A. (2012). Temperament type definition to patterns of papillary lines pointing fingers. Young scientist: scientific monthly, 1(36), 2.

Yarovenko, V. (2011). Criminalistics dermatoglyphics: Monograph. Vladivostok.

Yarovenko, V. (2013). Dermatoglyphic personality characteristics in the context of the determination of crime. Baikal Criminology Journal, 4(1), 36-40. Irkutsk.

Yarovenko, V. (2014). Form papillary pattern-like object of dermatoglyphic studies. Tomsk.

Yarovenko, V., \& Chistikin, A. (1994). Application system in medicine and forensic science: Scientific-method, 
allowance. Tyumen.

Yarovenko, V., \& Kitaev, N. (2014). Characteristics of dermatoglyphic traits of violent serial crimes. Law and policy, 11. Moscow.

Zoroastrov, M. (2006). Medico-legal aspects of the dynamics and genetic bases of suicide among residents of the Tyumen region. Moscow.

Zvyagin, V., \& Rakitin, V. (2012). Dermatoglyphics: Encyclopedic dictionary. Perm.

\section{Copyrights}

Copyright for this article is retained by the author(s), with first publication rights granted to the journal.

This is an open-access article distributed under the terms and conditions of the Creative Commons Attribution license (http://creativecommons.org/licenses/by/3.0/). 